\title{
Un debate entre dos siglos sobre educación y hegemonía en el nuevo capitalismo
}

4 Darío Pulfer y Ana Pereyra

\begin{abstract}
Resumen
El artículo reconstruye la trama de un debate entre Juan Carlos Tedesco y Emilio Tenti Fanfani, del que participa también Guillermina Tiramonti. El debate gira en torno al concepto de hegemonía en el nuevo capitalismo y las implicancias de estos enfoques para la educación y las políticas educativas. Los artículos de los tres autores fueron reunidos y publicados por la revista Propuesta Educativa de la Facultad Latinoamericana de Ciencias Sociales (FLACSO) en el año 2003.
\end{abstract}

El texto presenta las líneas fundamentales de la argumentación de cada uno de los participantes, los nudos decisivos de la discusión y sus implicancias para el mundo educativo.

La relevancia de estas ideas, sus resonancias en el presente, la creencia en la fecundidad de la conversación y el debate académicos nos impulsaron a recuperar estos textos.

\section{A debate between two centuries on education and hegemony in the new capitalism}

\begin{abstract}
The article reconstructs the plot of a debate between Juan Carlos Tedesco and Emilio Tenti Fanfani, of which Guillermina Tiramonti also participates. The debate focuses on the concept of hegemony in the new capitalism and the implications of these approaches for education and educational policies. The articles of the three authors were collected and published by the magazine Propuesta Educativa of the Latin American Faculty of Social Sciences (FLACSO) in 2003.
\end{abstract}

The text presents the fundamental lines of the argumentation of each one of the participants, the decisive knots of the discussion and their implications for the educational world.

\section{Palabras-claves:}

hegemonía, capitalismo, educación, sociedad, subjetividad.

\section{Keywords}

hegemony, capitalism, education, society, subjectivity. 
The relevance of these ideas, their resonances in the present, the belief in the fecundity of the conversation and the academic debate prompted us to recover these texts.

\section{Introducción}

En este artículo nos proponemos reconstruir la trama de un debate reflejado por la revista Propuesta Educativa (RPE) de la Facultad Latinoamericana de Ciencias Sociales (FLACSO) correspondiente al año 2003, en la que se pone de manifiesto un rasgo de la obra de Juan Carlos Tedesco, referido a la producción teórica. De manera adicional intentamos identificar las resonancias actuales de este debate pedagógico.

En un contexto complejo y crítico para la Argentina, en el que se auguraban los peores pronósticos, la $R P E$ recibe un material de Juan Carlos Tedesco proponiendo una reflexión que trasciende la inmediatez y la coyuntura: Notas e hipótesis sobre educación y hegemonía en el nuevo capitalismo. Acompaña el artículo una réplica al mismo elaborada por Emilio Tenti Fanfani.

La dirección de $R P E$, a cargo de Inés Dussel, reconociendo el valor de las argumentaciones de la polémica para el contexto local convoca a otros especialistas para que formen parte y "reaccionen" al debate.

En el desarrollo del texto presentamos las líneas fundamentales de la argumentación e integramos lo que consideramos los nudos decisivos de la discusión y sus implicancias para el mundo de la educación.

Nos interesa volver sobre estos materiales no solo como recuperación de la figura de Juan Carlos Tedesco, sino por la relevancia de las problemáticas que fueron abordadas, la recepción y trayectoria de estas ideas en el debate educacional argentino y latinoamericano y el bajo o nulo reconocimiento explícito de estas fuentes.

\section{Los protagonistas y la organización del debate}

1. Este material ya había sido enviado en julio del 2001, aceptado en octubre y publicado en la Revista de Educación, número extraordinario dedicado a Educación y Globalización en el que participan Gimeno Sacristán, Manuel Castels, Nicolás Burbules, Carlos

A. Torres, entre otros, $c f r$. Tedesco (2001). Por otra parte, retomaba argumentaciones vertidas en el libro publicado en el año 2000 por Fondo de Cultura Económica bajo el título Educar en la sociedad del conocimiento. Para el envío a la RPE, Tedesco agrega comentarios sobre lo acontecido el 11 de septiembre de 2001.

El sentido, entendemos, del envío del material a RPE corresponde al afán de circular un conjunto de ideas

en otro ámbito, siendo limitada la circulación de las revistas impresas y no estando disponibles aún en la red.
Juan Carlos Tedesco elabora su texto en el año $2001^{1}$ cuando se desempeñaba como director del IIPE-Unesco, Sede Regional Buenos Aires. Lo comparte con Emilio Tenti quien era el coordinador del área de investigación de ese instituto. Cuando Tenti le comenta a Tedesco su desacuerdo con la tesis de que "al capitalismo actual no le interesa la hegemonía", Tedesco le propone la elaboración de un artículo con su punto de vista.

Por otra parte, los especialistas convocados por la Dirección de la RPE para reaccionar al debate fueron Guillermina Tiramonti y Estanislao Antelo.

En su contribución, Guillermina Tiramonti se referencia en la polémica para comenzar a desplegar una hipótesis en torno a la fragmentación social y escolar que desarrollaría individual y colectivamente en los siguientes años. La participación de Estanislao Antelo no se integra finalmente en la publicación.

En la presentación dicen Inés Dussel y Nadine Poliak (2003): “Como siempre, Tedesco propone argumentos interesantes para pensar, esta vez sobre las características más generales de nuestra época y los desafíos que se presentan a la educación". 
Luego explican la intención de la convocatoria a otros autores: "El ensayo invita a debatir, y por eso nos propusimos pedir artículos que respondieran el convite discutiendo la dinámica de las instituciones heredadas de la modernidad y sus actuales modos de regulación social" (ibíd.).

En la presentación de $R P E$ el debate es inscripto en una perspectiva estratégica:

La intención del debate propuesto es recuperar una perspectiva de análisis de largo plazo. Aunque resulta una tarea nada fácil en una Argentina signada por la crisis del día a día, las temáticas que plantean y las posturas que sostienen cada uno de los tres autores escapan a la coyuntura y proponen miradas retrospectivas y profundas. (ibíd.)

Localizan como nudo del debate: el “... debilitamiento de una lógica claramente moderna: la vocación hegemónica de los sectores dirigentes y el papel de la escuela para el logro de tal fin" (ibíd.) atendiendo a las transformaciones de la familia y a la relevancia inaudita de los medios de comunicación masivos en la conformación de la opinión pública.

Al final de la presentación, las autoras se concentran en las notas principales de la dramática situación y acuden al concepto de crisis para definirla:

La eficacia de ese sistema hoy está en crisis. Por un lado, la crisis de la autoridad estatal la alcanza, aunque en menor medida que a otras instituciones y esferas de acción del Estado, pero lo suficiente como para poner en discusión su legitimidad y su capacidad instituyente. Hay otras instituciones (los medios de comunicación, el mercado, las relaciones horizontales entre pares o fraternidades) que parecen tener más capacidad de imponer sentidos y de aportar proyectos para el futuro. Por otro lado, los proyectos políticos colectivos e inclusivos también fueron golpeados. La crisis del Estado de bienestar a fines de los años ochenta, leída en clave neoliberal, contribuyó fuertemente a moldear el "imaginario social”, las creencias, las expectativas y los temores de nuestras sociedades. Lo colectivo se privatizó; las luchas por el bienestar tendieron a pensarse más en términos individuales que como acciones colectivas. Se impuso una hegemonía por neutralización, lograda en parte a través del silenciamiento de los otros discursos y del postulado acerca de la muerte de las ideologías, difundido por quienes propiciaban la tecnificación de la política y la despojaban de toda posibilidad de disenso respecto al modelo de normalidad establecido. A nivel del sistema educativo, la pérdida de un ideal y de proyectos políticos integradores, sumado a otros procesos económicos y sociales, también contribuyó a una fragmentación y discontinuidad cultural entre escuelas que atienden a distintos grupos sociales. Hoy las experiencias educativas de los chicos y los docentes son muy diferentes según se encuentren en uno u otro lugar del sistema. Esta diferencia poco tiene que ver con la diferencia cultural y el pluralismo que todos queremos; es una reproducción mucho más agravada de la desigualdad económica y cultural de nuestra sociedad. (ibíd.)

Aunque las presentadoras auguran una continuidad del debate en los años siguientes, esta prolongación no se produjo localmente en medios públicos. ${ }^{2}$

Poco tiempo después el "debate" Tedesco-Tenti fue republicado por la Revista Colombiana de Educación. ${ }^{3}$ Luego se produce un desdibujamiento del registro de la polémica que, hipotetizamos, obedece al eclipsamiento de las condiciones sociales y políticas que dieron lugar al material y que motivaron el intercambio. También, puede deberse, a la apertura de un nuevo ciclo de políticas educativas, a partir del año 2003, que tendrán a Tedesco como protagonista significativo.
2. La conversación-debate siguió en otros espacios de primer entorno: Tedesco fue uno de los especialistas invitados por Tenti al grupo de estudio sobre la relación entre educación y estructura social que animaba junto a Cora Steinberg y Analía Meo en el Instituto Gino Germani de la Facultad de Ciencias Sociales de la UBA para tratar estos temas contemporáneamente.

3. La Revista Colombiana de Educación publica el material en 2003. Los editores del debate señalan: "Este texto se publica con autorización de la directora de la revista Propuesta Educativa de la FLACSO, Inés Dussel". La fecha de recepción fue el 1 de octubre de 2003 y el arbitraje data del 17 de octubre de 2003 ". 
4. Como señalamos anteriormente el debate se desencadena cuando Tedesco se desempeñaba como director del IIPE Unesco y Tenti colaboraba en dicha institución. Desde allí sostienen, frente a los planteos de época del Banco Mundial, el planteo de la "educabilidad" y desarrollan un programa de investigación sobre la condición docente en el cono sur dirigido por Emilio Tenti.

5. Aunque Tedesco no lo menciona es importante destacar que, para Durkheim, la división del trabajo social solo es capaz de generar solidaridad orgánica (cohesión) en la medida en que es espontánea y que “... por espontaneidad es necesario entender la ausencia, no simplemente de toda violencia expresa y formal, sino de todo lo que puede trabar, incluso indirectamente, el libre desarrollo de la fuerza social que cada uno lleva en sí. Supone que los individuos no están relegados por la fuerza en funciones determinadas, sino además que ningún obstáculo, de cualquier naturaleza, les impida ocupar en los cuadros sociales el lugar que está en relación con sus facultades. En una palabra, el trabajo solo se divide espontáneamente si la sociedad está constituida de manera

tal que las desigualdades sociales expresen exactamente las desigualdades naturales" (Durkheim, 1902).

6. Aunque esta afirmación tiene alguna resonancia con el pensamiento de Durkheim, sería más ajustado sostener que el vivir juntos del capitalismo industrial al que refiere el autor requiere de esta creencia común (conciencia colectiva) acerca de la correspondencia biunívoca entre desigualdades naturales y sociales. Si el vivir juntos fuera una consecuencia natural del orden social como lo propone Tedesco,

sería difícil comprender la necesidad de postular a través de la escuela del capitalismo industrial un pensamiento hegemónico. Desde la perspectiva de Durkheim, en cambio, la falta de espontaneidad en el proceso de división social del trabajo constituye una anomalía ya que "una clase de la sociedad, para vivir, está obligada a vender a cualquier costo sus servicios, mientras que la otra puede pasarse sin ellos, gracias a los recursos de que dispone y que, no obstante, no son necesariamente debidos a alguna superioridad social. De esta manera, la segunda, injustamente, dicta la ley a la primera. Dicho de otro modo, no pueden existir ricos y pobres de nacimiento sin que haya contratos injustos" (Durkheim, 1902: 377). El carácter activo que Durkheim le atribuye a la Educación Moral (que podemos considerar aquí como la promoción de un pensamiento hegemónico) se vincula a la persistencia de un fenómeno, una anomalía que inhibía el carácter espontáneo de la división del trabajo social. Anomalía que, en principio, Durkheim había concebido como transitoria y remediable. La Educación Moral a través del cuerpo de docentes funcionando como sacerdotes laicos tiene como base de sustento la creen-

cia, en ese momento generalizada, que hacía corresponder desigualdades naturales y desigualdades sociales.
Como veremos, en lo que sigue, Tedesco, Tenti y Tiramonti acuerdan en la caracterización de la crisis. No obstante, mientras Tedesco y Tenti localizan en la política y particularmente en la escuela, un camino posible en la reconstitución de lo común, Tiramonti descarta esta opción anteponiendo el nivel de fragmentación del sistema educativo y su acentuación creciente. Tenti responde puntualmente a los argumentos de Tedesco, contradiciéndolo. Por esa razón centramos el artículo en el contrapunto establecido entre Tedesco y Tenti y separamos los comentarios realizados por Guillermina Tiramonti.

Vale una aclaración: aun cuando en este texto se presentan los términos de lo que podríamos considerar un debate producido por las características del comentario, réplica del escrito de Emilio Tenti, resulta importante subrayar otros acuerdos existentes, para la misma época, entre ambos amigos en torno a categorizaciones tales como la educabilidad, la equidad en las políticas educativas y la focalización en la cuestión docente. $^{4}$

\section{Los argumentos}

Tedesco sostiene en su ensayo la tesis de que el capitalismo actual no tiene vocación hegemónica, y que eso produce una situación de desintegración y de fragmentación social inauditas en la historia. Para su argumento, revisa lo que viene sucediendo no solo en las escuelas, sino también en las familias y en los medios de comunicación, y destaca un quiebre en la transmisión de una herencia cultural compartida.

El argumento de Juan Carlos Tedesco se estructura alrededor de un contrapunto entre el capitalismo industrial comparado con el actual. Parte de referenciarse en Durkheim para sostener que la cohesión del capitalismo industrial reside en el proceso de división social del trabajo generador de solidaridad orgánica. La especialización ocupacional relaciona a todos los individuos entre sí (recordemos que este es el argumento que emplea Durkheim para explicar cómo es posible que al mismo tiempo los individuos se vuelvan más autónomos y dependan más estrechamente de la sociedad) y "a todos los sectores sociales a través de relaciones de explotación y dominación” (Durkheim, 1902 citado por Tedesco, 2003).

De aquí se deriva el carácter "incluyente" del capitalismo industrial ${ }^{5}$ que se expresa en el hecho de que, en el capitalismo industrial, "vivir juntos es una consecuencia natural del orden social". ${ }^{6}$

A un conjunto de rasgos constitutivos del capitalismo industrial como serían el carácter incluyente a partir del establecimiento de vínculos de dominación y explotación con todos los sectores sociales, el vivir juntos como consecuencia natural del orden social y, la postulación de un pensamiento hegemónico a partir de instituciones (escuela y medios de comunicación) basadas en la lógica de la oferta (para todos lo mismo), Tedesco le contrapone los rasgos del nuevo capitalismo. Este último lo caracteriza por su carácter excluyente (ruptura de los vínculos generados fundamentalmente a partir de la inserción laboral), el vivir juntos como consecuencia de una decisión política y, finalmente, el debilitamiento del pensamiento hegemónico, entendiendo por este último, un pensamiento capaz de convencer y generar adhesión.

La ausencia de vocación hegemónica del nuevo capitalismo constituye el núcleo central de su argumento y se corresponde con una lógica institucional basada en la demanda (adecuación institucional a perfiles diversos de los clientes). 
Los cambios que Tedesco señala en la composición y los vínculos familiares vienen a fortalecer la tesis del debilitamiento del pensamiento hegemónico del nuevo capitalismo. Las familias del capitalismo industrial -propone Tedesco- estuvieron organizadas a partir de vínculos indisolubles entre conyugalidad y filiación, del principio de autoridad (paterna) y en función de la transmisión a los hijos de una determinada visión del mundo (modelo prefigurativo de Mead) acorde a la tradición. En cambio, en las familias del nuevo capitalismo, la conyugalidad (social, electiva, temporaria) está disociada de la filiación (natural, según Tedesco) y las familias están organizadas según un principio democrático, centrado en el presente y donde se privilegia el intercambio orientado a la construcción de las identidades personales. Se torna preeminente, entonces, un modelo posfigurativo (Mead) en el que son los jóvenes los que enseñan los modelos significativos de conducta.

En este marco, se inscribe también el pasaje de la organización escolar desde la lógica de la oferta a la de la demanda, esto es desde una situación en la que había una discusión pública de los marcos de referencia comunes a la lógica clientelar de un individualismo asocial y privatista.

Tedesco (2003) concluye su texto estableciendo los dos pilares conceptuales a partir de los cuales se torna necesario organizar la escuela: aprender a aprender y aprender a vivir juntos. Se trata de dos procesos que ocurren a lo largo de toda la vida y dejan, por lo tanto, amplio margen de autonomía en las escuelas. Son estas precisamente las que deben programar experiencias de aprendizaje significativas, discutidas socialmente, "humanas", vale decir, "capaces de trascender los determinismos". En este contexto, el lugar protagónico de la escuela es el de reponer la idea de una cultura común, con valores y principios, lo que él llama un "núcleo duro", ético y cultural que nos permita vivir en común, y que contribuya a conformar una nueva sociedad más democrática e inclusiva.

Tenti comienza su intervención lisonjero con su antagonista. Señala que, citando a Deleuze, prefiere los textos que lo ayudan a pensar a aquellos que postulan verdades. De inicio señala que no asistimos al fin de la hegemonía: "Debo decir que la tesis del fin de la hegemonía en las sociedades capitalistas actuales no me satisface. Mi primera reacción fue responder la provocación (debería decir la invitación a la discusión) con otra provocación" (Tenti Fanfani, 2003). Frente a la tesis de Tedescto, Tenti sostiene que:

Lo que a primera vista pareciera ser un debilitamiento de la intención de conquistar la hegemonía (por parte de los poderosos de hoy) no es más que un síntoma de la más completa y económica realización de la misma. El supuesto subyacente es que el capitalismo no solo domina en la realidad de los procesos de producción y distribución de bienes y servicios, sino que también domina sobre las conciencias. (ibíd.)

Tenti organiza su texto de crítica a la tesis de Tedesco en torno a dos ejes básicos. El primero se centra en los modos de producción y reproducción de la hegemonía. El segundo, en el papel de las instituciones de socialización (industria cultural, familia y escuela) en la formación de la subjetividad de los agentes sociales.

Respecto a los modos de producción y reproducción de hegemonía, el primer señalamiento crítico del texto de Tenti se concentra en el carácter voluntario, intencional que Tedesco le adscribe al pensamiento hegemónico, o sea en ese punto ciego de su artículo que transita entre el vivir juntos del capitalismo industrial como consecuencia natural del orden social y la necesidad de promover un pensamiento hegemónico. Punto ciego que se prolonga en la postulación de la ausencia de vocación hegemónica del nuevo capitalismo. 
Tenti inscribe su argumento sobre el carácter no intencional ni voluntario del proceso de producción y reproducción de hegemonía en el pensamiento de Gramsci y en el de Max Weber. "El concepto de hegemonía - dice Tenti- tiene un linaje. Desciende directamente del uso gramsciano del término y tiene su raíz sistemática en la clásica distinción weberiana entre poder y dominación" (2003).

En la nota al pie que sigue a esta afirmación Tenti recupera los conceptos de poder y de dominación en Max Weber: "Poder significa la probabilidad de imponer la propia voluntad, dentro de una relación social, aun contra toda resistencia y cualquiera que fuera el fundamento de esa probabilidad". "Por Dominación debe entenderse la probabilidad de encontrar obediencia a un mandato determinado contenido entre personas dadas" (Weber, 1982 citado por Tenti Fanfani, 2003).

Y destaca que el concepto de dominación se asocia con el de legitimidad. "La dominación -dice Tenti-implica cooperación (es decir, aceptación, consenso, credibilidad, etcétera) del dominado en la producción y reproducción de la dominación. $Y$ es aquí donde la dominación se encuentra con la idea gramsciana de hegemonía" (2003).

A través de los conceptos weberianos de dominación y de legitimidad, Tenti enfatiza el aspecto voluntario (consensual) por parte de los dominados en las relaciones de dominación mientras Tedesco pone el acento en la intencionalidad de los sectores poderosos.

El planteamiento de Tedesco -dice Tenti- le agrega un elemento definitorio que solo recupera una de las formas posibles de su producción y reproducción. En efecto, escribe Tedesco en un texto anterior que: “Hegemonía significa, en este contexto, la voluntad (las itálicas son mías - de Tenti-) de imponer al conjunto de la población, los contenidos culturales, la visión del mundo, propia del sector social dominante. (Tedesco, 2000 citado por Tenti Fanfani, 2003)

En efecto,-sigue Tenti-creo que la hegemonía no es solo el producto de una voluntad o intencionalidad expresa de determinados actores colectivos, sino que también es el resultado de ciertos automatismos que resultan de la propia interiorización de la exterioridad (para usar una expresión de Habermas) que prescinde de toda voluntad e intencionalidad subjetiva logrando su consecución por otros medios y con otros resultados. (2003)

Tenti reconoce de esta manera en el planteo de Tedesco su contribución en el señalamiento de una diferencia específica: un cambio en el modo de ejercicio de la dominación en el nuevo capitalismo, pero eso lo lleva a sostener no la ausencia de hegemonía, sino la presencia de otro modo de producción y reproducción de la misma: la naturalización y la legitimación del orden social que genera por sí misma la participación en el consumo. En cuanto a las características de este nuevo modo de producción de la hegemonía en el nuevo capitalismo, Tenti señala:

a. es tácito e indirecto, pero tanto o más efectivo que cualquier programa explícito de inculcación (típico del esfuerzo civilizatorio de los primeros sistemas educativos del capitalismo nacional/estatal). En las condiciones actuales, los sistemas de producción y difusión de significados, al actuar en el marco del mercado y no perseguir adoctrinar ni convencer, sino vender y hacer dinero, terminan convenciendo y adoctrinando a través de la formación de una cultura popular que alimenta una demanda de productos que ellos están predispuestos a satisfacer, en un círculo que no se rompe sin crítica y decisión colectiva. En otras palabras, los medios educan sin proponérselo.

b. Puede prescindir de la escuela y además es más económico. Por eso algunos hasta han llegado a proponer el liso y llano desmantelamiento de esa vieja institución y su 
reemplazo por el autoaprendizaje sostenido en las nuevas tecnologías de la información y la comunicación.

En cuanto al papel de las instituciones de socialización en la subjetividad de los agentes sociales, la segunda crítica de Tenti se sostiene sobre el concepto de exclusión para dar cuenta de los cambios que operan tanto en la socialización primaria como en la secundaria, los dos mecanismos de producción y reproducción de la hegemonía de los poderosos.

\begin{abstract}
Me inclino a pensar -dice Tenti- que existen dos novedades: la primera es que a mayor exclusión y desigualdad mayor es la necesidad de hegemonía -entendida como consenso, como legitimidad, etcétera-; la segunda es que esta hegemonía hoy no precisa de acciones explícitas de inculcación, al estilo clásico del primer capitalismo: es decir, un ejército de maestros y escuelas que tienen por función civilizar, inculcando en la población un habitus determinado: el habitus capitalista. Hoy, hay hegemonía por el peso de las cosas. (2003)
\end{abstract}

Esta segunda crítica evoca a Bourdieu y apunta al modo en que grupos que ocupan posiciones diferentes en el espacio social construyen sus habitus, sus representaciones sociales, sus creencias colectivas, sus disposiciones:

... lo que no está en crisis porque no puede estarlo -señala Tenti- es lo que en el siglo XIX se llamaba la educación objetiva o educación de las cosas. En este sentido, la casa donde se habita, el lugar que se ocupa en la familia, el tipo de familia, el barrio, la lengua que se habla, la comida que se come, los lugares que se transita, la ropa que se viste, etcétera educan. Precisamente esto sucede cuando no se reconoce cuánto de no institucional, de no formal, de espontáneo, de natural y no calculado tiene el proceso de socialización. La confusión puede encontrar origen en una especie de sobrevaloración de una visión pedagogicista de la transmisión cultural: que supone ámbitos institucionales especializados, un contenido a transmitir (una referencia absoluta), las mediaciones, etcétera. (2003)

Para el autor-crítico se sigue produciendo un orden legítimo en las sociedades, que se apoya precisamente en el debilitamiento de ciertos lazos sociales y políticos que antes eran estructurantes. La transmisión, que es para Tenti una acción hegemónica, no es el resultado de una acción deliberada; los medios y la socialización familiar y de otras instituciones son productores de hegemonía también, aun cuando actúen de formas inéditas y diferentes a las viejas formas escolares. La tesis que sostiene el artículo de Tenti -en contraposición a la de Tedesco- es que el desplazamiento en el nuevo capitalismo de las agencias estatales de subjetivación -básicamente la escuela- por parte del mercado y los medios de comunicación ha sido exitoso en términos de producción y reproducción de la hegemonía. En este sentido, para Tenti (2003), en el capitalismo actual oferta y demanda están profundamente imbricadas y las viejas instituciones de socialización como la familia y la escuela se debilitan mientras los medios masivos de comunicación se concentran y generan una demanda de consumidores a su imagen y semejanza.

Sin embargo, para Tenti la desinstitucionalización que vienen sufriendo las escuelas y los sistemas educativos no es una fatalidad, producto de lógicas totalmente ajenas e ingobernables. Considera indispensable identificar las políticas y estrategias que la causaron para plantear acciones políticas con capacidad de revertirlas.

Ante la crisis y el dislocamiento de los actores sociales y políticos de la Argentina de ese momento, Tedesco recurre al voluntarismo de base individual. Tenti retoma esta iniciativa, pero le imprime una connotación que evoca el papel de los intelectuales en el pensamiento gramsciano: 
Pero pese a la novedad y complejidad de la situación no debemos renunciar al ejercicio de la razón. Una razón que no es una razón abstracta y eterna, sino histórica y contingente, pero al mismo tiempo operativa y eficiente, tanto para producir explicaciones plausibles como para orientar la acción. Para ello no estamos completamente desarmados. Podemos movilizar las mejores armas que nos ofrece la tradición intelectual de las ciencias humanas y sociales. Pero estas armas (teorías, sistemas conceptuales, estrategias metodológicas, etcétera) no están allí listas para ser utilizadas y aplicadas. Ellas tienen que ser adecuadas a las particularidades de los desafíos actuales, y esta es una tarea que excede las capacidades del intelectual tradicional individual. Por eso es más urgente que nunca darle forma a ese intelectual colectivo, único actor que está en condiciones de enfrentar con cierta probabilidad de éxito la inmensa tarea de proveer explicaciones plausibles necesarias para orientar la acción en estos tiempos difíciles que vivimos. El trabajo de Tedesco es un aporte a esta construcción necesaria y este es quizás el mejor elogio que se le puede dispensar. (2003)

Precisamente, la confluencia entre Tedesco y Tenti se produce alrededor de la confianza en el desarrollo de un nuevo programa para la escuela, al que postulan como contra-cultural.

Comparto totalmente con Tedesco -dice Tenti- su planteamiento acerca de las dos ideas rectoras de un programa educativo del siglo XXI: el aprender a aprender y el aprender a vivir juntos. Es preciso recordar, justamente con Tedesco, que la escuela, dadas determinadas condiciones que es preciso analizar y conquistar, debe constituirse en un lugar de contra cultura o de cultura contrahegemónica.

$Y$ todo esto hay que hacerlo sin caer en el pedagogicismo ingenuo propio de la década del sesenta (la escuela liberadora). Por eso hay que ser realistas y proponerse una política de la escuela capaz de proveer a esta institución de todos los recursos, no solo financieros, sino también institucionales, culturales, pedagógicos, didácticos, como para que pueda competir con éxito con los medios de comunicación en esta formidable tarea de construir sujetos humanos conscientes y críticos, pero también sabios y competentes. (2003)

\section{La intervención de Guillermina Tiramonti}

Tiramonti coincide con Tenti en el diagnóstico del debilitamiento institucional y el carácter preeminente del mercado y pone el acento en describir cómo estas transformaciones impactaron en el Estado y diferencialmente a distintos sectores sociales.

La crítica va por lo que, a su juicio, vela el discurso universalizante de Tedesco del aprender a aprender y a vivir juntos:

Lo primero a señalar es que se trata de una definición única y general para todas las escuelas y con esto el autor pasa por alto el problema de la pérdida de centralidad del Estado y de la fragmentación social y su correlato en la educación. (Tiramonti, 2003)

Basada en sus investigaciones señala que:

... se identificaron heterogéneos patrones culturales para la socialización de los jóvenes que las instituciones construyen en diálogo con las clientelas que atienden y las condiciones socio-culturales en las que habitan. En esta construcción hay escasas o nulas referencias al Estado a excepción de las escuelas de esta dependencia, donde igualmente su capacidad regulatoria es limitada. (ibíd.) 
Desde su perspectiva, la propuesta de Tedesco es sesgada en tanto:

Las estadísticas muestran que el circuito público atiende a los sectores medios/bajos y bajos de la población, todos ellos habitantes de la vulnerabilidad. De modo que, para decirlo crudamente, Tedesco hace una propuesta educativa solo implementable en el circuito público focalizado, hoy día, en la atención de los pobres. (ibíd.)

Y se plantea, forzando la argumentación de Tedesco:

Es para ellos que se reclama la reposición de un núcleo duro desde el cual ¿socializar, disciplinar o moralizar? Me pregunto cuál es el principio ético que animará este proceso de socialización y proporcionará el fundamento de una pedagogía que nos permita vivir juntos. O mejor dicho que les permita a los perdedores vivir junto a los ganadores en un sistema en el que se han roto los lazos de dependencia y por lo tanto las obligaciones morales que relacionaban a unos con otros. (ibíd.)

Cuestiona el plan y el sentido de posicionar la escuela como alternativa contracultural:

Sin duda, es posible idear una escuela en la que se recreen experiencias que no tienen lugar en la cultura externa, basadas en los principios de respeto, solidaridad y responsabilidad, y esto será un aporte positivo en los procesos de construcción identitaria de los chicos. Sin embargo, me pregunto cuál es la funcionalidad de construir un marco institucional contra-cultural. (ibíd.)

Retomando la cuestión de la transmisión familiar, Tiramonti señala que la transmisión no se actualiza en algunas familias, en particular por motivos vinculados a la crisis económica, política y social; en otras palabras, no es que no haya transmisión, sino que ese capital heredado de las familias tiene menos valor en las condiciones actuales para algunos sectores que para otros. “¿De qué sirven hoy las estrategias de las clases obreras y de las clases medias laboriosas de los años cincuenta en un marco de tanto desempleo y falta de perspectiva?", se pregunta (ibíd.).

Tiramonti reintroduce la variable de la clase social y la fragmentación para argumentar que la crisis no tuvo iguales efectos sobre todos, y que no es solo con otros valores y principios que va a reconstruirse un proyecto de inclusión social.

\section{Fuentes, nudos de la polémica y resonancias actuales para el pensamiento pedagógico}

Resulta interesante, después del tiempo transcurrido, volver sobre estos materiales que pusieron en cuestión temas centrales en relación a la tarea de educar en las sociedades contemporáneas. Al considerar ese tema entra en juego el papel de la escuela en el nuevo escenario.

Si bien el planteo nacía de una situación concreta -como era la de la Argentina sumergida en la peor crisis económica y social vivida hasta entonces-, aunque justificado bajo "la urgencia del largo plazo", no dejaba de trascender sus límites.

En esa reconstrucción aparecen referencias a autores extranjeros -sobre todo franceses- receptados y recreados casi en simultáneo con su momento de salida como son Touraine, Castel, Rosanvallon, Fitoussi, Cohen, lo que hoy constituye un mapa de los materiales en circulación y uso en el mundo de la producción intelectual en torno a la educación. Cabe señalar la influencia de la obra de Castel (1997) con la idea que 
7. Ambos citan la versión original francesa de 1999. más impacta en la reflexión sobre la ausencia de hegemonía en el nuevo capitalismo: la exclusión. Está tomada en términos casi idénticos a sujetos prescindibles desde el punto de vista de los sectores dominantes y el sistema.

En la línea de la recepción de estos materiales resulta sugestiva e interesante la utilización para fines diversos, entre ambos antagonistas, de una misma fuente bibliográfica (Boltansky y Chiapello, 2002). ${ }^{7}$ Tedesco enmarca el mundo actual con la categorización de "nuevo capitalismo" que toma de los autores. Tenti utilizará la obra para referir a las cuestiones ideológicas, a la necesidad de un espíritu o sentido para los actores en el funcionamiento del capitalismo actual.

Este debate puede constituirse en un testimonio de época en la medida que expresa una línea de interrogación en un contexto de baja o nula capacidad estatal, de crisis social pavorosa, de desdibujamiento del horizonte colectivo.

Refleja una violenta introspección por parte de protagonistas del campo intelectual que buscan dar una explicación a una situación en la que no encuentran base para hacer pie.

La lenta recomposición del escenario político con las elecciones del 2003, el activismo gubernamental de la primera etapa del gobierno de Néstor Kirchner, la reactivación económica y los procesos que llevaron a una nueva legalidad e intervención del ministerio nacional reposicionaron a los actores.

En la polémica aparecen una serie de temas que se fueron tornando lugar común en los análisis del mundo educativo tales como: caracterizaciones sobre el nuevo modo de producción en el capitalismo, las características de la dominación en esta etapa, los procesos de subjetivación contemporánea, y el papel de las industrias culturales, las familias y las escuelas en estos procesos.

De los temas que conservan plena actualidad nos interesa concentrarnos en el vínculo entre Estado, mercado y neoliberalismo como modo de intervención en la producción / regulación de las sociedades actuales y destacar la relevancia de la discusión en torno a la diversidad entre quienes la conciben como un elemento potencialmente democratizador y quienes enfatizan su carácter disruptivo de la articulación política y social.

En cuanto al primer asunto cabe señalar que el uso de Gramsci que Tenti hace en su réplica a la tesis de Tedesco es marginal en la estructuración de su argumento. Es relevante considerar que -en forma análoga al momento en que se desencadena esta polémica- el concepto de hegemonía, Gramsci lo formula en condiciones de derrota del campo popular. Gramsci delinea la forma en que el adversario de clase restablece su dominio y su hegemonía a través de la operación que consiste en individualizar los siempre nuevos niveles de recomposición unitaria de lo social. Por tal motivo, este modo de reproducción de la hegemonía no es nuevo. Lo novedoso entonces sería su eficacia sobre sectores sociales crecientemente excluidos del mundo del trabajo y el papel de las nuevas agencias de subjetivación, fundamentalmente los medios de comunicación.

Asimismo, la relación que Tenti establece: a mayor exclusión, más hegemonía se formula por fuera de un análisis de las relaciones de fuerza y del concepto de relaciones sociales de modo tal que la identidad social de los excluidos del mundo del trabajo no se problematiza en este planteo. En la perspectiva de Gramsci, las relaciones de fuerza refieren al modo total en que se estructura, desde lo económico a lo político una sociedad construida sobre el antagonismo de clase, y de representar su marcha como una sucesión de distintos resultados de la confrontación de las fuerzas en lucha. "El conjunto de las relaciones sociales en las que los hombres reales se mueven y actúan es el único capaz de refundar el concepto idealista de subjetividad que de este modo 
se entiende como subjetividad de un grupo social" (Gramsci, 1985: 191). De allí que, para Gramsci, "la discusión versa sobre la medida de las fuerzas subjetivas y de su intensidad, y en consecuencia sobre la relación dialéctica entre las fuerzas subjetivas en contraste" (Gramsci, 1984: 74).

Camino hacia nuestra actualidad, durante el período 2003-2015, la construcción política de una alternativa ante la crisis que da ocasión a esta polémica, fue pensada tomando como una de sus referencias el pensamiento de Laclau. Precisamente, Laclau y Mouffe se distancian del pensamiento gramsciano sobre la hegemonía en tanto:

\begin{abstract}
Reposa sobre una concepción... que no logra superar plenamente el dualismo del marxismo clásico. Porque, para Gramsci, incluso si los diversos elementos sociales tienen una identidad tan solo relacional, lograda a través de la acción de prácticas articulatorias, tiene que haber siempre un principio unificante en toda formación hegemónica, y este debe ser referido a una clase fundamental. Con lo cual vemos que hay dos principios del orden social (la unicidad del principio unificante y su carácter necesario de clase) que no son el resultado contingente de la lucha hegemónica, sino el marco estructural necesario dentro del cual toda lucha hegemónica tiene lugar. Es decir, que la hegemonía de la clase no es enteramente práctica y resultante de la lucha, sino que tiene en su última instancia un fundamento ontológico. La infraestructura no asigna a la clase obrera su victoria, sino que esta depende de su capacidad de liderazgo hegemónico; pero a una falla en la hegemonía obrera solo puede responder una reconstitución de la hegemonía burguesa. La lucha política sigue siendo, finalmente, un juego suma-cero entre las clases. Este es el último núcleo esencialista que continúa presente en el pensamiento de Gramsci. (2004: 80)
\end{abstract}

La conclusión a la que arriban Laclau y Mouffe mediante esta crítica al pensamiento de Gramsci es que la lógica de hegemonía reside en la articulación y la contingencia. Entienden por articulación una práctica que establece relaciones entre elementos de tal manera que la identidad de los mismos es modificada como resultado de dicha práctica. Se trata de una práctica fundamentalmente discursiva que se despliega en el terreno de la lucha política sujeta a contingencias, aunque siempre incluye momentos de fuerza y represión. La articulación y la contingencia condicionan la no fijación de la identidad social y la ausencia de un vínculo necesario entre la tarea y la clase. Mientras que para Gramsci (1984) se es aristócrata en la medida que se es plebeyo, para Laclau y Mouffe (2004) la identidad de los agentes sociales tiene un carácter puramente relacional en tanto se construye a partir de su articulación en el interior de una configuración discursiva hegemónica.

Sobre esta base referencial (Laclau-Mouffe) la construcción discursiva del gobierno se apoyó en la disputa: sectores populares-corporaciones económicas concentradas.

En base al enfoque de derechos se organizaron un conjunto de políticas inclusivas que si bien lograron una mejora en la distribución del ingreso no interrumpieron la subjetivación como consumidores de los sectores populares, subjetivación que constituye el núcleo central de esta polémica.

Las políticas educativas como lo anticiparon Tedesco y Tenti se organizaron en torno al concepto de inclusión conforme a los lineamientos directrices de la Ley de Educación Nacional del 2006 y en el marco de la conceptualización precedente.

No obstante, es posible identificar en el campo educativo un conjunto de iniciativas que fueron más allá de las transferencias condicionadas de ingreso y que estuvieron orientadas al logro de las metas estratégicas de la construcción de lo común y la formación de sujetos humanos conscientes y críticos, pero también sabios y competentes formuladas 
8. Aunque niegue la voluntad hegemónica sigue pensando la cuestión social en esos términos. respectivamente en sus exposiciones por Tedesco y Tenti. La producción de recursos para el aula vinculados al Programa Conectar Igualdad, la creación del Instituto Nacional de Formación Docente (INFOD) como organismo orientado a producir lineamientos comunes ante un sistema formador en extremo fragmentado y el diseño de dispositivos apropiados a la finalización de la educación obligatoria por parte de los jóvenes y adultos (FinEs) constituyen ejemplos elocuentes de diseños de política que se distancian tanto de la lógica de la polarización apuntando a la construcción de lo común como de las políticas orientadas centralmente al fortalecimiento del consumo.

Los intercambios presentados en este artículo constituyen una muestra o pliegue de una práctica intelectual y de la constitución de un espacio de análisis y debate que pueden ser útiles tanto para la historia de las ideas como para volver a leerlos y preguntarnos sobre vigencias e implicancias para los tiempos que corren.

En particular, nos sirven para recuperar la figura y el pensamiento de Juan Carlos Tedesco en su faz conceptual, en la que podemos identificar rasgos de continuidad entre aquel joven con tintes gramscianos de Educación y Sociedad ${ }^{8}$ hasta el intelectual público que sigue manteniendo la preocupación por lo común y por las cuestiones vinculadas a la hegemonía, la sociedad y la escuela desde una matriz relacional.

Aunque no lo hemos desarrollado aquí, las discusiones sobre la diversidad cultural tienen plena vigencia y dan lugar a un conjunto de preguntas ligadas al núcleo de este debate: ¿qué es lo común o cómo pensar la ciudadanía en el capitalismo actual?, ¿es posible desarrollar un modelo pedagógico que dé lugar a sujetos reflexivos y a la vez competentes o la irreversibilidad de la fragmentación y la consolidación de la subjetivación consumista torna banal el pensamiento pedagógico?, ¿qué lugar ocupan las instituciones formadoras y cuál los medios de comunicación en la construcción de las capacidades ligadas al ejercicio clásico de la hegemonía y de la ciudadanía en un marco de crecimiento continuo de sectores sociales desvinculados del mundo del trabajo? 


\section{Referencias bibliográficas}

» Boltansky, L. y Chiapello, E. (2002). El nuevo espíritu del capitalsmo. Madrid, Akal.

»Castel, R. (1997). Metamorfosis de la cuestión social. Una crónica del salariado. Buenos Aires, Paidós.

"Comisión Internacional sobre la Educación para el Siglo XXI (1996). La educación encierra un tesoro. Madrid, Santillana - Unesco.

"Congreso Nacional de Argentina. (14 de diciembre de 2006). Ley de Educación Nacional. [Ley 26206 de 2006].

»Durkheim, E. (1902). De la division du travail social, pp. 370-371. París, Alcan.

»Dussel, I. y Poliak, N. (2003). Introducción. En Propuesta Educativa, núm. 26.

》 Gramsci, A. (1984). Notas sobre Maquiavelo, sobre la política y sobre el Estado moderno, pp. 74. Buenos Aires, Nueva Visión.

»__. (1985). El materialismo histórico y la filosofía de Benedetto Croce, pp.191. Buenos Aires, Nueva Visión.

»Laclau, E. y Mouffe, CH. (2004). Hegemonía y Estrategia socialista. Hacia una radicalización de la democracia, pp. 80. México, Fondo de Cultura Económica.

»Tedesco, J. C. (2000). Educar en la sociedad del conocimiento. México, Fondo de cultura Económica.

》__. (2001). Educación y hegemonía en el nuevo capitalismo: algunas notas e hipótesis de trabajo. En Revista de Educación, núm. extraordinario, pp. 91-99. En línea: <https://www.mecd.gob.es/revista-de-educacion/numeros-revistaeducacion/numeros-anteriores/2001/re2001/re2001_07.html> (consulta: 31/10/2017).

》__. (2003). Educación y hegemonía en el nuevo capitalismo: algunas notas e hipótesis de trabajo. En Propuesta Educativa, núm. 26.

»Tenti Fanfani, E. (2003). Notas sobre la escuela y los modos de producción de la hegemonía. En Propuesta Educativa, núm. 26.

» Tiramonti, G. (2003). En búsqueda del orden perdido. En Propuesta Educativa, núm. 26.

»Weber, M. (1982). Economía y sociedad, pp. 43. México Fondo de Cultura Económica.

\section{Bibliografía ampliatoria}

»Tedesco, J. C. (1986). Los paradigmas de la investigación educativa. En Revista colombiana de educación, núm. 18. Bogotá, Universidad Pedagógica Nacional. En línea: <http://revistas.pedagogica.edu.co/index.php/RCE/article/ view/5152/4223>. (consulta: 02-11-2017).

»Tenti Fanfani, E. (2003). La escuela y los modos de producción de la hegemonía. En Universidad de San Buenaventura, sitio web de la biblioteca: < http://biblioteca. usbbog.edu.co:808o/Biblioteca/BDigital/28735-07.pdf> (consulta: 03-11-2017). 


\section{Breve currículum de los/as autores/as}

\section{Darío Pulfer}

Licenciado en Educación, Universidad de San Andrés. Director del Departamento de Educación y Ciencias Sociales de la Universidad Pedagógica Nacional (UNIPE), Argentina. Director del Centro de Documentación e Investigación acerca del Peronismo, Universidad Nacional de San Martín (CEDINPE-UNSAM), Argentina. Correo electrónico: pulferdario@gmail.com

\section{Ana Pereyra}

Doctora en Ciencias Sociales, Facultad Latinoamericana de Ciencias Sociales (FLACSO). Magister en Ciencia Política, Instituto de Altos Estudios Sociales (IDAES), Universidad Nacional de San Martín. Licenciada en Sociología, Universidad de Buenos Aires. Secretaria de Investigación de la Universidad Pedagógica Nacional (UNIPE), Argentina. Correo electrónico: anapereyra770@gmail.com 